\title{
Prenatal growth, subsequent marital status, and mortality: longitudinal study
}

Denny Vågerö, Bitte Modin

Centre for Health Equity Studies of Stockholm University and Karolinska Institute (CHESS),

University, S-106 91 Stockholm, Sweden Denny Vågerö professor Bitte Modin researcher

Correspondence to: Denny Vågerö denny.vagero@ chess.su.se

BMJ 2002;324:398
We replicated the studies undertaken by Phillips et al to test their propositions that early growth restriction which they claim leads people to remain unmarried is linked with the susceptibility to cardiovascular disease and that the link between marital status and health may have its origin during intrauterine life. ${ }^{2}$

\section{Methods and results}

The Uppsala birth cohort study is a lifelong follow up study of people born in 1915-29. ${ }^{34}$ We used official registers to follow their marital status and mortality from 1970 through to 1995 . Complete data were available for 5577 men and 5227 women. We collected school results at age 10 and body height (for men) at conscription (age 18) for a random sample of 405 boys and 411 girls $(8 \%)$.

To indicate fetal growth we calculated birth weight for gestational age, since this predicts cardiovascular disease better than birth weight alone. ${ }^{3}$ Birth weight for gestational age, divided into fifths, showed an association with later marital status for men but not women. In the lowest fifth nearly $12 \%$ of men remained unmarried, a figure that is 3.0-4.5\% higher than in the upper three fifths; the odds ratio (adjusted for year of birth and mother's age) was 1.51 (95\% confidence interval 1.14 to 2.01 ) when the lowest fifth was compared with the highest. Further adjustment for adult socioeconomic factors (known from 1960 and 1970 censuses), parents' social class, and marital status at childbirth changed this odds ratio by less than $1 \%$.

Men born to unmarried women tended more often than other men to be unmarried themselves (odds ratio 1.55, 1.21-1.99; adjusted for year of birth and mother's age); additional adjustment for birth weight by gestational age hardly affected this estimate.

Phillips et al suggested that this link between early growth and later marital status provided some explanation of the differences in mortality associated with adult marital status. We compared the mortality ratios (total, ischaemic heart disease, and stroke) of never married and ever married people before and after adjusting for early biological and social factors (birth weight by gestational age, marital

Mortality of never married compared with ever married men aged 41-80 ( $n=5577)$

\begin{tabular}{lccc} 
& \multicolumn{3}{c}{ Mortality ratio of never married to ever married men } \\
\cline { 2 - 4 } Adjustment & Total & Ischaemic heart & disease \\
\hline Birth year and mother's age & $1.63(1.41$ to 1.88$)$ & $1.43(1.10$ to 1.85$)$ & 2.91 (1.74 to 4.87$)$ \\
\hline plus birth weight for gestational age & $1.64(1.42$ to 1.89$)$ & $1.41(1.09$ to 1.83$)$ & $2.88(1.72$ to 4.84$)$ \\
\hline $\begin{array}{l}\text { plus marital status and social class at } \\
\text { birth }\end{array}$ & $1.65(1.43$ to 1.91$)$ & $1.42(1.09$ to 1.84$)$ & 2.74 (1.63 to 4.61$)$ \\
\hline $\begin{array}{l}\text { plus adult occupation, income, and } \\
\text { education }\end{array}$ & $1.19(1.02$ to 1.39$)$ & $1.06(0.80$ to 1.41$)$ & 2.14 (1.22 to 3.76$)$ \\
\hline
\end{tabular}

status of the mother, and social class at birth), and three adult socioeconomic factors (occupation, education, and income). Never married women were not significantly different from ever married women; risk estimates were always near unity. The table shows the corresponding results for men. Ratios are large yet changed little on adjustment for birth weight by gestational age; they did not change when social factors at birth were adjusted for. Controlling for adult factors, in contrast, had a substantial effect.

\section{Comment}

Our evidence supports a link between fetal growth and subsequent marital status for boys but not girls; boys whose growth was slowest were least likely to marry. Being born out of wedlock seems as powerful in its effect on later marital status as birth weight.

Growth retardation resulting from the mothers' intake of alcohol, tobacco, or other toxic substances may affect facial proportions, ${ }^{5}$ and certain aspects of growth retardation may therefore lead to subtle disadvantage later in life. We found that men who subsequently never married had been less successful in school and shorter at age 18 , by an average of $1 \mathrm{~cm}$ (data not shown).

Differences associated with marital status in rates of ischaemic heart disease or stroke are unlikely to have their roots in restriction of prenatal growth. Adult occupation, income, and education were far more important.

Our results partly support the findings of Phillips et al. Biological and social factors evolve together and influence each other, but, in spite of this, prenatal growth may not explain why unmarried people have higher death rates.

We thank Dave Leon for important comments.

Contributors: DV and BM conceived and wrote the paper. $\mathrm{BM}$ collected data on marital status and analysed the data. DV is the guarantor.

Funding: The study was funded by the Swedish Council for Social Research.

Competing interests: None declared.

1 Phillips DIW, Handelsman DJ, Eriksson JG, Forsén T, Osmond C, Barker DJP. Prenatal growth and subsequent marital status: longitudinal study. BMJ 2001;322:771.

2 Phillips DIW, Handelsman DJ, Erikson JG, Forsén T, Osmond C, Barker DJP. Is marital status determined prenatally? Poster presented at the first world congress on the fetal origins of adult disease, Mumbai, India, 3 February 2001 (in press).

3 Leon DA, Lithell HO, Vågerö D, Koupilová I, Mohsen R, Berglund L, et al. Reduced fetal growth and increased risk of ischaemic heart disease mortality-cohort study of 15000 Swedish men and women born 191529. BMJ 1998:317:241-5.

4 Vågerö D, Leon DA, Koupilová I, Lithell UB. Social determinants of birth weight, ponderal index and gestational age in Sweden in the 1920s and the 1980s. Acta Paediatr 1999; 88:445-454.

5 Olsen J, Tuntiseranee P. Is moderate alcohol intake in pregnancy associated with the craniofacial features related to the fetal alcohol syndrome? Scand J Soc Med 1995;23:156-61.

(Accepted 1 November 2001) 